\section{Effects of compression on performance and regeneration}

\section{Helmut Lötzerich \\ Institute of Outdoor Sports and Environment Science, German Sport University, Cologne, Germany}

The benefits of stockings in sports are discussed under various conditions. The current results are evaluated with different methods like treadmill running, bicycle ergometers, jumping performances or peak power. Furthermore, the compression of stockings varied from elastic clothes with unknown compression to less elastic stockings, but mainly compression class I or II are used. Different manufacturers of compression garments (different compression values, production tolerances, fitting problems) are the reason that there is no comparability between the different research results. Currently, no study shows a decrease of performance caused by compression garments. For example, in a maximum treadmill running test or in a $40 \mathrm{~km}$ cycling time trail, increased performance could be demonstrated when athletes wore compression garments. ${ }^{1,2}$ Taken together, positive effects of performance or regeneration or wellbeing caused by compression garments are shown in $60 \%$ of the current studies. Optimal recovery is the guarantee to positively reach a higher training frequency in combination with higher intensities. The advantage of compression garments during regeneration is that athletes need no time in comparison to others recovery strategies like massage, active recovery, cryotherapy, contrast temperature water immersion, hyperbaric oxygen therapy, stretching, humidification therapy or electrostimulation. The positive effects on delayed onset muscle soreness or rating of perceived exertion are clearly shown in the majority of studies after 24,48 or $72 \mathrm{~h}$. But there are no or only little but not significant changes in performance (endurance, strength) or biological markers like, CK, CrP, myoglobin, lactate dehydrogenase, interleukin (IL)-6 or IL-10. Finally, athletes and coaches have only little knowledge of the benefit of stockings in recovery. On the other hand a lot of marathon runners and soccer players are using the stocking during competition. Therefore, we need detailed and basic information about the positive effects of stockings in all kind of sports.
Correspondence: Helmut Lötzerich, Institute of Outdoor Sports and Environment Science, German Sport University, Am Sportpark Muengersdorf 6, 50933 Cologne, Germany.

E-mail: loetzerich@dshs-koeln.de

This work is licensed under a Creative Commons Attribution 4.0 License (by-nc 4.0).

CC Copyright H. Lötzerich, 2016

Licensee PAGEPress, Italy

Veins and Lymphatics 2016; 5:5993

doi:10.4081/vl.2016.5993

\section{References}

1. Kemmler W, von Stengel S, Köckritz C, et al. Effect of compression stockings on running performance in men runners. J Strength Cond Res 2009;23:101-5.

2. Hamlin MJ, Mitchell CJ, Ward FD, et al. Effect of compression garments on shortterm recovery of repeated sprint and 3-km running performance in rugby union players. J Strength Cond Res 2012;26:2975-82. 